\title{
Evaluation of accelerated real-time CMR using sparse sampling with iterative SENSE reconstruction in patients and volunteers
}

\author{
Bradley D Allen ${ }^{1 *}$, Maria Carr ${ }^{1}$, Michael O Zenge ${ }^{2}$, Michaela Schmidt ${ }^{2}$, Mariappan S Nadar ${ }^{3}$, Bruce S Spottiswoode $^{4}$, \\ Jeremy D Collins ${ }^{1}$, James C Carr ${ }^{1}$
}

From 17th Annual SCMR Scientific Sessions

New Orleans, LA, USA. 16-19 January 2014

\section{Background}

The use of gated CMR can be limited by motion artifacts secondary to cardiac and respiratory motion. Imaging is especially challenging in patients with arrhythmias or those who cannot perform adequate breath-holds. Realtime CMR is a non-gated technique that has been successfully applied in scenarios where standard segmented acquisitions break down. In this study, we sought to accelerate real-time acquisition by using sparse sampling with an iterative SENSE reconstruction.

\section{Methods}

Seven consecutively recruited patients undergoing nonemergent CMR (58 \pm 18 years, $\mathrm{M}: \mathrm{F}=3: 4)$ and 6 volunteers $(38 \pm 11$ years, $\mathrm{M}: \mathrm{F}=4: 2)$ were included in this IRB-approved study. CMR was performed at $1.5 \mathrm{~T}$ (MAGNETOM Aera, Siemens Healthcare, Erlangen, Germany). The examination included acquisitions of standard segmented SSFP (iPAT2) (GRAPPA accel factor 2, TR $\left.40 \mathrm{msec}, 2.1 \times 2.1 \times 10 \mathrm{~mm}^{3}\right)$ cine, standard real time (TPAT3) (TPAT accel factor 3, TR $62 \mathrm{msec}$, $2.9 \times 2.9 \times 7 \mathrm{~mm}^{3}$ ), and the investigational prototype sparsely sampled SSFP with iterative SENSE reconstruction with $\mathrm{L} 1$ regularization along one spatial and temporal dimension $\left(\operatorname{SPARSE}_{\mathrm{i}}\right.$ 9.9) (accel factor 9.9, TR 43 msec, $2.0 \times 2.0 \times 7 \mathrm{~mm}^{3}$ ) (1). Each technique was used to acquire a three-, four-chamber, and short axis series in identical slice positions (Figure 1), with coverage of the entire left ventricle (LV) and $10 \mathrm{~mm}$ interslice gaps. Individual slice scan times were recorded. Quantitative LV functional analysis was performed. A reviewer

${ }^{1}$ Radiology, Northwestern University, Chicago, Illinois, USA Full list of author information is available at the end of the article blinded to acquisition type scored images for overall image quality, noise, and artifacts using a 5-point Likert scale. Continuous variables were compared between groups using a paired t-test, and ordinal variables were compared using a Wilcoxon signed-rank test.

\section{Results}

In a combined analysis of patients and volunteers, there was no significant difference between LV ejection fraction

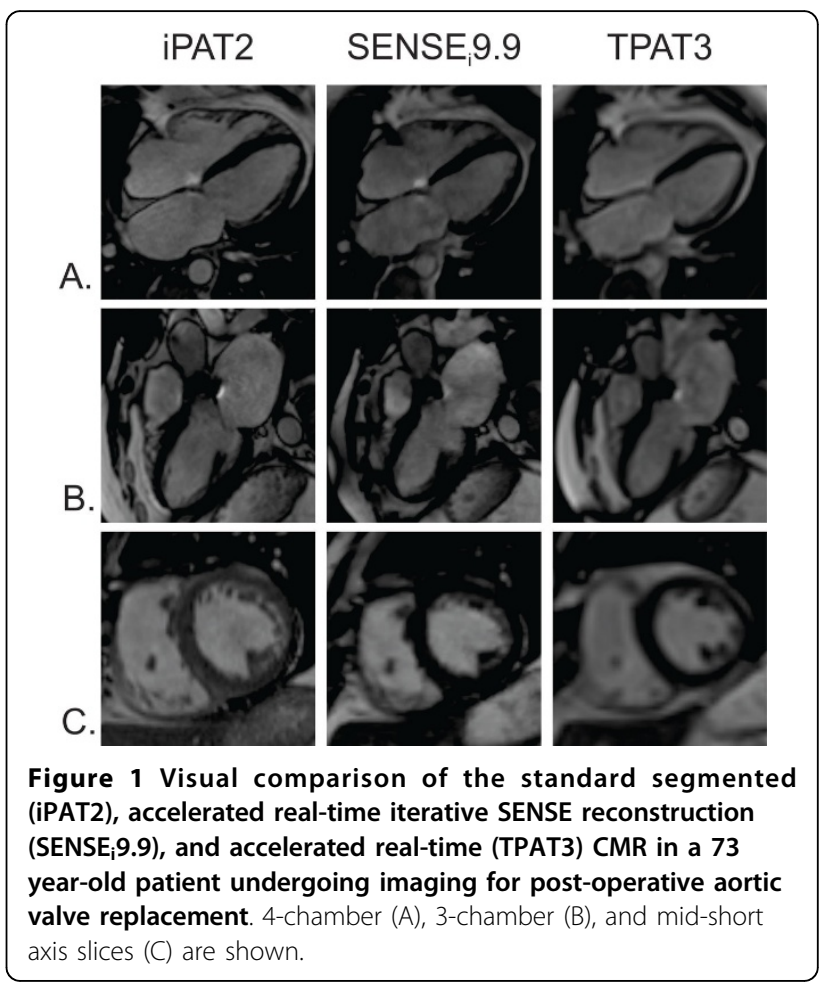




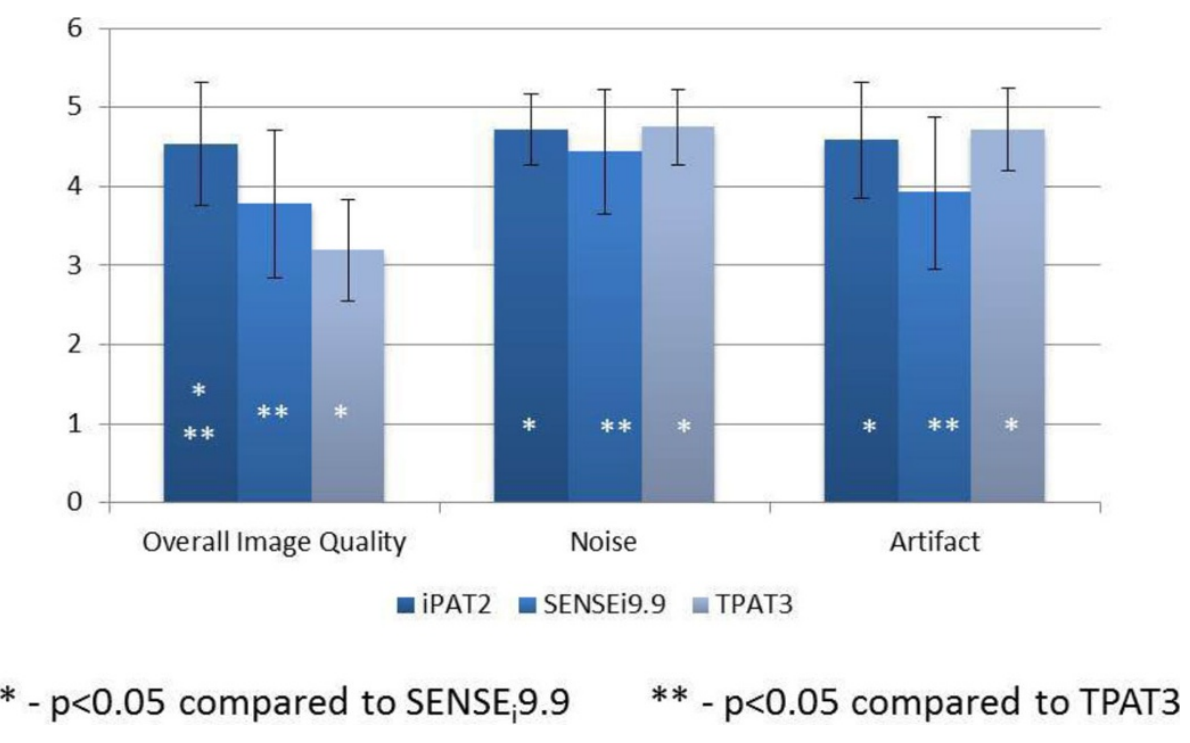

Figure 2 Qualitative analysis in patients and volunteers.

between iPAT2 and SPARSE $9.9(\mathrm{p}=0.18)$ or TPAT3 $(\mathrm{p}=0.31)$, and there was no difference between either real time acquisition ( $\mathrm{p}=0.83)$. The iPAT2 technique measured higher myocardial mass than SPARSE $9.9(105 \pm 25$ g vs. $95 \pm 30 \mathrm{~g}, \mathrm{p}=0.004)$ and TPAT3 $(86 \pm 26 \mathrm{~g}, \mathrm{p}<$ $0.001)$. The iPAT2 technique was superior to both SPAR$\mathrm{SE}_{\mathrm{i}} 9.9(\mathrm{p}<0.001)$ and TPAT3 $(\mathrm{p}<0.001)$ in overall image quality. The SPARSE 9.9 group had higher image quality compared to TPAT3 ( $<<0.001)$, but TPAT3 had marginally reduced noise $(\mathrm{p}=0.01)$ and reduced artifact $(\mathrm{p}<$ 0.001). (Figure 2) Short axis slice acquisition times were shorter for SPARSE $\mathrm{i}_{\mathrm{i}} 9.9(3.8 \pm 0.6 \mathrm{sec})$ than iPAT2 $(8.9 \pm$ $1.5 \mathrm{sec}, \mathrm{p}<0.001)$ and TPAT3 $(5.7 \pm 1.0 \mathrm{sec}, \mathrm{p}<0.001)$.

\section{Conclusions}

Highly accelerated real-time CMR using sparse sampling with iterative SENSE reconstruction can be successfully applied in patients and volunteers with accurate calculation of LV functional parameters. Image quality is reduced relative to gold-standard segmented acquisitions, but is superior to standard real-time acquisitions. 1. Liu J, et al. ISMRM 20th Annual Meeting. Melbourne, Australia, 2012:4249.

\section{Funding}

NIH NCI 5R25CA132822-04.

\section{Authors' details}

${ }^{1}$ Radiology, Northwestern University, Chicago, Illinois, USA. ${ }^{2}$ Siemens AG Healthcare Sector, Erlangen, Germany. ${ }^{3}$ Siemens Corporate Technology, Princeton, New Jersey, USA. ${ }^{4}$ Siemens Healthcare USA, Inc., Chicago, Illinois, USA.
Published: 16 January 2014

\section{doi:10.1186/1532-429X-16-S1-012}

Cite this article as: Allen et al.: Evaluation of accelerated real-time CMR using sparse sampling with iterative SENSE reconstruction in patients and volunteers. Journal of Cardiovascular Magnetic Resonance 201416 (Suppl 1):012.
Submit your next manuscript to BioMed Central and take full advantage of:

- Convenient online submission

- Thorough peer review

- No space constraints or color figure charges

- Immediate publication on acceptance

- Inclusion in PubMed, CAS, Scopus and Google Scholar

- Research which is freely available for redistribution 